\title{
openheart Consultant staffing in UK congenital cardiac services: a 10-year survey of leavers and joiners
}

\author{
David Steven Crossland (D , ${ }^{1}$ Richard Ferguson, ${ }^{2}$ Alan Magee, ${ }^{3}$ Petra Jenkins, ${ }^{4}$ \\ Frances A Bulock, ${ }^{5}$ Andrew Parry, ${ }^{6}$ Sonya V Babu-Narayan, ${ }^{7}$ Aisling Carroll, ${ }^{8}$ \\ Piers EF Daubeney, ${ }^{9}$ John Simpson ${ }^{10}$
}

\begin{abstract}
- Additional online supplemental material is published online only. To view, please visit the journal online (http://dx.doi.org/10.1136/ openhrt-2021-001723).
\end{abstract}

To cite: Crossland DS, Ferguson R, Magee A, et al. Consultant staffing in UK congenital cardiac services: a 10-year survey of leavers and joiners. Open Heart 2021;8:e001723. doi:10.1136/ openhrt-2021-001723

Received 17 May 2021 Accepted 21 June 2021
Check for updates

(c) Author(s) (or their employer(s)) 2021. Re-use permitted under CC BY-NC. No commercial re-use. See rights and permissions. Published by BMJ.

For numbered affiliations see end of article.

\section{Correspondence to} Dr David Steven Crossland; david.crossland@nhs.net

\section{ABSTRACT}

Objectives To report the numbers of consultant congenital cardiac surgeons and cardiologists who have joined and left UK practice over the last 10 years and explore the reasons for leaving.

Methods Retrospective observational questionnaire study completed between 11 June 2019 and 1 July 2020 by UK level 1 congenital cardiac centres of 10-year consultant staff movement and reasons suggested for leaving UK practice.

Results At survey completion there were 218 (202 whole time equivalent (WTE)) consultant cardiologists and surgeons working within level 1 centres made up of 39 (38 WTE) surgeons, 137 (128.5 WTE) paediatric cardiologists, 42 (35.5 WTE) adult congenital heart disease (ACHD) cardiologists. $161(74 \%)$ consultants joined in the last 10 years of whom $103(64 \%)$ were UK trained. There were 91 leavers giving a staff turnover rate $42 \%$ (surgeons $56 \%$, paediatric cardiologists $42 \%$, ACHD cardiologists $29 \%$ ). Of those, leaving $43 \%$ moved to work abroad (surgeons $55 \%$, paediatric cardiologists $40 \%$, ACHD cardiologists $67 \%$ ). Among the 65 reported reasons for leaving 16 were financial, 9 for work life balance, 6 to working conditions within the National Health Service (NHS) and 12 related to the profession in the UK including six specifically highlighting the national review process.

Conclusions There has been a high turnover rate of consultant staff within UK congenital cardiac services over the last 10 years with almost half of those leaving moving to work overseas. Financial reasons and pressures relating to working in the NHS or the specialty in the UK were commonly reported themes for leaving. This has major implications for future planning and staff retention within this specialised service.

\section{INTRODUCTION}

Congenital cardiac services are commissioned in the UK as National Health Service England (NHSE) specialised services with surgery and intervention for children and adults delivered in one of 16 surgical (level 1 centres). ${ }^{1}$ Centres provide these level one services through 11 networks (six networks have level 1 services for adults and children at the same site and five have paediatric

\section{Key questions}

What is already known about this subject?

- There are significant concerns about staff retention and staff turnover rates within the National Health Service (NHS).

- Congenital cardiac services have been under considerable scrutiny over the last 30 years.

- A review has set standards for congenital cardiac services which include consultant staff numbers for congenital cardiologists and surgeons.

What does this study add?

- The consultant staff turnover rate over the last 10 years in in congenital cardiology and cardiac surgery was $42 \%$ with $36 \%$ of new posts filled by consultants undergoing their specialist training outside the UK.

- The most common reason to leave is for posts outside the UK ( $43 \%$ of leavers) as opposed to retirement $(25 \%)$. Financial factors and reasons related to working in the NHS including the review process commonly cited as explanations for leaving UK practice.

- The number of adult congenital heart disease consultants currently employed is approximately a third of the number required to meet NHS England standards.

How might this impact on clinical practice?

- Improving the training opportunities of congenital heart disease (CHD) specialists, particularly those in surgery and adult CHD cardiologists, would promote recruitment to meet national requirements.

- Addressing the reasons for staff leaving practice in the UK would both improve staff numbers and retain expertise within the NHS.

- Structured exit interviews of senior clinical staff members leaving the NHS may become the rule rather than the exception.

and adult services at geographically distinct sites). There is much subspecialisation within congenital cardiology and clinical practice is both challenging and highly rewarding. 
The specialty requires considerable teamwork across all areas. Most procedural decision making is made at multidisciplinary team meetings quorate with surgeons, the range of cardiology subspecialties and the wider team. Services have been under considerable scrutiny over the last 30 years including individual unit reviews, the safe and sustainable review of congenital heart disease (CHD) services and the New Review of CHD services. ${ }^{2-8}$ In parallel to this, there has been continued development of the National Congenital Heart Disease Audit managed by the National Institute for Cardiovascular Outcomes Research. Data reporting is obligatory and is rigorously externally audited to ensure its high quality, in contrast to the self-reported data used in many other specialties and countries. ${ }^{910}$ National outcomes have been, and remain, among the best in the world and continue to improve, with the crude 30-day mortality for CHD surgery in children falling from $3.2 \%$ in $2008 / 2009 \%$ to $1.4 \%$ in $2017 / 2018 .^{10}$ Serial national reviews culminated in service standards being set by NHSE in 2016. ${ }^{478}$ Included in these are minimum staffing numbers for units, which has implications for consultant staffing for many centres. Meeting these standards is dependent on the development of new posts, recruiting into these and ensuring consultant retention. Staff retention within the National Health Service (NHS) as a whole and the movement of NHS staff to work abroad has raised considerable concerns. ${ }^{11-13}$ The British Congenital Cardiac Association (BCCA) is aware of a number of high profile consultant departures. There have been few previous surveys describing NHS consultant leavers within individual specialties and the reasons for this. ${ }^{14}$

Congenital cardiology and congenital cardiac surgery require long and highly specialised training. ${ }^{15-17}$ While this training provides a considerable amount of clinical and technical expertise, the specialty also relies on its more experienced team members. Newly appointed consultants in all areas, in particular cardiac surgery and interventional cardiology, are often mentored by more experienced consultants for a period of time. Dual operator practice is actively encouraged. ${ }^{17}$ Many patients require lifelong high-quality care and develop a close partnership with their treating team. To understand the impact of these various issues on the UK congenital cardiac consultant workforce, the BCCA set out to establish the numbers of consultants in congenital cardiac services who have joined and left UK practice over the last 10 years and explore possible reasons for consultants leaving.

\section{METHODS}

A retrospective observational questionnaire study was sent to paediatric and adult congenital heart disease (ACHD) lead clinicians from each UK level 1 congenital cardiac centre/ network. Questionnaires were completed between 11 June 2019 and 1 July 2020. Details of new posts, consultant staff joining and leaving as well as colleague reported reasons for leaving over the preceding 10-year period were collected to allow an approximation of staffing levels and staff movement between January 2010 and January 2020. Numerical and comments questions were open ended. The 10-year staff turnover rate was calculated as:

Turnover rate $=$ number of leavers $/($ staff in $2010+$ staff in 2020) $/ 2$

Questions related to three professional groups were included: congenital cardiac surgeons, paediatric cardiologists and ACHD cardiologists. These questions included the reasons for consultants leaving as reported by their colleagues and whether an exit interview was conducted routinely. Data for cardiac surgeons, paediatric cardiologists and ACHD cardiologists are reported separately as these groups have distinct training pathways as discussed below. The open-ended questions about colleague reported reasons for leaving were divided into seven groups and categorised into these groups by two of the authors (DSC and JS). In cases where the authors categorised the responses into different groups these were resolved by direct discussion. The groups were:

1. Personal.

2. Financial.

3. NHS related (non-salary).

4. UK CHD profession related.

5. Work life balance.

6 . Research and training.

7. Other.

Patients and public were not involved in this study.

\section{Participation and response rates}

Seventeen questionnaires were completed with contribution from 19 consultant members of staff (in two units two consultants completed the questionnaire together). Replies were available for all congenital centres with respect to practice in children (11 of 11) and 8 out of a possible 11 for ACHD practice (table 1).

\section{RESULTS}

At the time of survey completion, there were 218 (202 whole time equivalent (WTE)) consultant cardiologists and surgeons working within congenital cardiac services. There were 39 (38 WTE) surgeons, 137 (128.5 WTE) paediatric cardiologists and 42 (35.5 WTE) ACHD cardiologists (table 2). There were at least 15 vacant posts. The subspecialty paediatric cardiologist posts are shown in table 3. Six of 11 paediatric units did not have a consultant with an interest in paediatric heart failure or in pulmonary hypertension and two did not have a consultant with an interest in inherited cardiac conditions. Nine paediatric units rely on a single operator for electrophysiology and seven have a single consultant specialising in cross sectional imaging (CT/MRI). Consultants with more than one subspecialty interest account for the difference between total subspecialty posts and total number of paediatric cardiologists. 
Table 1 Units contributing questionnaire and the areas of the questionnaire responded to by each unit

\begin{tabular}{ll}
\hline Contributing unit & Groups involved \\
\hline University Hospital Southampton & Paediatric, ACHD \\
Evelina Childrens Hospital/Guy's \& St Thomas' & Paediatric, ACHD \\
NHS Foundation Trust & \\
\hline Great Ormond Street Hospital for Children & Paediatric \\
\hline Royal Brompton \& Harefield NHS Foundation & Paediatric, ACHD \\
Trust & \\
\hline Birmingham Children's Hospital & Paediatric \\
University Hospital Birmingham & ACHD \\
\hline $\begin{array}{l}\text { University Hospitals Bristol NHS Foundation } \\
\text { Trust }\end{array}$ & Paediatric, ACHD \\
Leeds Children's Hospital/Leeds General & Paediatric, ACHD \\
Infirmary & \\
\hline Royal Hospital for Children, Glasgow & Paediatric \\
\hline $\begin{array}{l}\text { Alder Hey Children's Hospital/ North West } \\
\text { Congenital Cardiac Services }\end{array}$ & Paediatric \\
\hline Freeman Hospital, Newcastle upon Tyne & Paediatric, ACHD \\
East Midlands Congenital Heart Centre, \\
Leicester
\end{tabular}

ACHD, adult congenital heart disease; NHS, National Health Service.

Details of the consultants leaving and joining within each group are shown in table 2 . Within the last 10 years, there were 161 consultants appointed (joiners) representing $74 \%$ of the current workforce. Of these $84(52 \%)$ were into newly created posts with 103 (64\%) of joiners being recruited from UK trainees. Over the time period 91 consultants left the specialty (leavers), giving a 10-year
Table 3 Subspecialty paediatric cardiologists posts in 2020

\begin{tabular}{lcc}
\hline $\begin{array}{l}\text { Paediatric cardiology } \\
\text { subspecialty }\end{array}$ & $\begin{array}{l}\text { Median per } \\
\text { centre (range) }\end{array}$ & Total \\
\hline Fetal cardiology & $5(1-6)$ & 36 \\
\hline MRI/CT & $1(1-5)$ & 23 \\
\hline Electrophysiology & $1(1-2)$ & 14 \\
\hline Interventional cardiology & $3(3-5)$ & 42 \\
\hline Heart failure & $0(0-8)$ & 18 \\
\hline Advanced echo & $2(1-6)$ & 24 \\
\hline Pulmonary hypertension & $0.5(0-2)$ & 7 \\
Inherited cardiac disease & $1.5(0-5)$ & 20 \\
\hline Ward consultant & $0(0-3)$ & 3 \\
\hline
\end{tabular}

consultant staff turnover rate of $50 \%$. In all three groups the most common reason to leave was to move abroad (55\% of surgeons, $40 \%$ of paediatric cardiologists, $67 \%$ of ACHD cardiologists who left moved abroad). This equates to staff turnover for posts abroad of $35 \%$ among surgeons, 20\% among paediatric cardiologists, 24\% among ACHD cardiologists and $23 \%$ in total.

\section{Colleague reported reasons for leaving}

Four $(24 \%)$ of the responses reported that exit interviews are routinely held. Sixty-five reasons for leaving were given. The number of responses in each category is shown in table 4. Of those leaving for UK profession related reasons (12 responses), six cited that the reason was related to the ongoing review processes. Among the seven categorised as 'other', Brexit was given as the

Table 2 Consultant staff working within UK congenital cardiology level one centres and detail of leavers and joiners between 2010 and 2020

\begin{tabular}{|c|c|c|c|c|}
\hline & Surgeons & Paediatric cardiologists & ACHD cardiologists & Total \\
\hline \multicolumn{5}{|l|}{ Total employed } \\
\hline January 2010 & 30 & 93 & 25 & 148 \\
\hline January 2020 (WTE) & $39(38)$ & $137(128.5)$ & $42(35.5)$ & $218(202)$ \\
\hline Median (range) per unit 2020 & $3(3-5)$ & $10(6-28)$ & $5(3-7)$ & - \\
\hline \multicolumn{5}{|l|}{ Joiners } \\
\hline Join in past 10 years (\%) & $31(79)$ & $101(74)$ & $29(69)$ & $161(74)$ \\
\hline UK trained (\%) & $14(45)$ & $68(67)$ & $21(72)$ & $103 / 161(64)$ \\
\hline New posts (\%) & $10(32)$ & $54(53)$ & $20(69)$ & $84 / 161(52)$ \\
\hline \multicolumn{5}{|l|}{ Leavers/ Turnover rate $(\mathrm{ToR} \%)^{\star}$} \\
\hline Left in past 10 years (ToR\%) & $22(64)$ & $57(50)$ & $12(36)$ & $91(50)$ \\
\hline Retired (\% of leavers, ToR\%) & $7(32,20)$ & $15(26,13)$ & $1(8,3)$ & $23(25,13)$ \\
\hline UK move ( $\%$ of leavers, ToR\%) & $3(14,9)$ & $12(21,10)$ & $3(25,9)$ & $18(20,10)$ \\
\hline Move abroad (\% of leavers, ToR\%) & $12(55,35)$ & $23(40,20)$ & $8(67,24)$ & $43(47,23)$ \\
\hline Unknown (\% of leavers, ToR\%) & 0 & $7(12,6)$ & 0 & $7(8,4)$ \\
\hline
\end{tabular}

${ }^{*}$ ToR- Staff turnover rate calculated as: staff turnover rate=number of leavers / (staff in 2010+staff in 2020)/2.

ACHD, adult congenital heart disease; WTE, whole time equivalent. 
Table 4 Reason to leave category frequency of the 65 reported reasons for leaving

\begin{tabular}{ll}
\hline Reason to leave category & $\begin{array}{l}\text { No of times given as } \\
\text { a reason for leaving }\end{array}$ \\
\hline Personal & 10 \\
\hline Financial & 16 \\
\hline NHS related & 6 \\
\hline $\begin{array}{l}\text { UK congenital heart disease profession } \\
\text { related }\end{array}$ & $12^{\star}$ \\
Work life balance & 9 \\
\hline Research and training & 5 \\
\hline Other & $7 \dagger$ \\
\hline
\end{tabular}

${ }^{*} 6$ relating to the national review process or resultant scrutiny.

$\dagger 3$ relating to Brexit.

reason in 3 cases. The full list of responses is available as online supplemental file 1 and included:

- 'Hostile environment to paediatric congenital cardiology/cardiac surgery over last decade'.

- 'Threat to centre existence'.

- 'Restriction to service development due to NHS resources'.

- 'Lack of control over one's own destiny'.

- 'Better research funding'.

- 'Better recognition'.

\section{DISCUSSION}

We report the first detailed assessment of consultant congenital cardiologist and consultant congenital cardiac surgeon staffing within the UK and as far as we are aware the first such report of any consultant group within NHS England's specialised services. The total number of consultant positions has expanded considerably over the last 10 years. A net gain of 44 paediatric cardiologists to 128.5 WTE approaches the required figure suggested by the 2016 NHS England standards of 1 paediatric cardiologist per 0.5 million population (estimated 2020 requirement of 132 paediatric cardiologist for a population of 66 million). ${ }^{489}$ However, there is an ongoing shortage of some subspecialty practitioners such as heart failure and inherited cardiac conditions. Many units rely on a single consultant for electrophysiology and crosssectional imaging. In addition, demand for subspecialists in inherited cardiac conditions and heart failure in children is currently not being met. The total number of congenital cardiac operations carried out in the UK each year is 5500 and the NHS standard is for a minimum number of 125 operations per surgeon per year. ${ }^{810}$ This suggests number of cardiac surgeons is sufficient based purely on caseload. The total number of ACHD cardiologists, however, raises significant concern. More than $95 \%$ of infants born with cardiovascular anomalies can now expect to reach adulthood. ${ }^{18}$ These ACHD patients now make up more than half of the congenital heart disease patients in the UK, with the UK population of ACHD patients increasing by at least 16000 over this 10-year period. ${ }^{1920}$ Many of our most complex patients, in particular single ventricle patients, are only now starting to reach adulthood. Despite this increasing population and complexity there are only 35.5 WTE ACHD cardiologists in the UK. Although three level 1 units did not complete the survey subsequent personal communication with units who did not respond/data on their websites show that were a maximum of 45 WTE ACHD cardiologists at the beginning of 2020. The current standards outline a need for one ACHD WTE for a maximum of 1500 ACHD patients. ${ }^{8}$ The estimated population prevalence of ACHD is 4 in 1000 and the current UK adult population is 52 million which requires an estimated 138 WTE ACHD cardiologists. ${ }^{121}$ The UK, therefore, currently has less than a third of the desired number of ACHD cardiologists to meet current demand. At least one additional WTE is required each year to manage the ongoing 'graduates' from paediatric care with the increase in ACHD cardiologists accounting for this population growth as opposed to a real expansion in the workforce. ${ }^{20}$

Among all three groups, we have shown that recruitment to these positions has relied heavily on staff who have undergone their higher specialist training outside the UK; more than a third trained abroad. This was particularly marked for congenital cardiac surgeons, with only $45 \%$ of new appointments in the last 10 years filled by UK specialist trainees. Others have shown a similar change with all the expansion in UK congenital cardiac surgeons between 1999 and 2014 filled by non-UK graduates and a fall in the percentage of UK graduate congenital surgeon from $70 \%$ to $54 \%$ over the same time period. ${ }^{22}$ Reliance on consultants trained abroad raises significant concerns for the sustainability of the service within the UK, particularly with likely changes to both certification equivalence and recruitment from Europe as result of Brexit (see below) ${ }^{23}$ Willingness of staff from abroad to come to the UK to work may be regarded as positive for the specialty although this needs to be balanced against the numbers leaving UK practice. A 10 -year staff turnover rate of $50 \%$ (37\% excluding retirement), or $5 \%$ per annum, appears high. It is double the calculated staff turnover rate among neurosurgeons between 2014 and 2018 for whom similar data are available. ${ }^{14}$ Some staff movement within the UK ( $10 \%$ turnover rate) is expected with career progression and might be considered desirable to spread expertise between units. However, the majority of those leaving units moved abroad, particularly among surgeons, with a $35 \%$ staff turnover rate (55\% of all surgical leavers) to work abroad over the 10-year period. Across all three specialties, retirement made up only $25 \%$ of all those leaving compared with neurosurgery where $60 \%$ of those vacated posts due to retirement. Our observation is that many of those leaving were experienced clinicians resulting in a drain of a highly experienced resource and raising the probability that conditions and opportunities in the UK played a role in their decision making. Inevitably some will leave for personal reasons, but UK professional reasons and financial were more frequently cited. The former included excessive scrutiny (described as 
'hostile' by one respondent). There have been concerns about breakdown in collaboration between units, due to prolonged attempts to restructure the national delivery of care causing uncertainty and reduced morale, particularly in units believed to be 'at risk'. In addition, limitations in access to operating time and frustration in lack of adequate postoperative facilities were identified as reasons for surgeons moving abroad, where the resources were perceived as being superior. The new standards have not been matched by resource allocation to congenital cardiac services. The pressure of external enquiries, direct unit comparisons and the requirement to achieve minimum case numbers has forced units to compete against each other for their survival. Furthermore, despite continuing improvement in outcomes, the (although understandable) intense scrutiny of mortality or morbidity and the drive to improve further, adds pressure, especially on the operators, perpetuates anxieties and may encourage risk avoidance. ${ }^{22}$ The fact that the highest turnover rate was among surgeons and that most left to work abroad suggests that working within the NHS is not perceived as attractive by many congenital cardiac surgeons. This requires urgent attention if the highest quality staff are to be trained and retained within the UK.

There was not sufficient additional information to explore the financial incentives to move. Funding of the congenital cardiac services, NHS funding as a whole and financial packages offered in North America and the Middle East, as well as limited scope for private practice within the UK for congenital heart disease, are likely to have played a part. Erosion of the UKs international reputation and lack of research/developmental opportunities were also identified as reasons to leave UK practice. It is striking that only one quarter of units surveyed held an exit interview for consultant staff leaving their unit. We believe that structured exit interviews should be mandatory for all consultants leaving their unit, if detailed first-hand information is to be available for future analysis and workforce planning.

Many of the reasons highlighted for leaving UK practice are likely to influence the career choices of junior medical staff when considering a career in congenital cardiac services. These decisions are also be influenced by other factors such as early career exposure and delivery of training. The current entry and training requirements are shown in table 5 . UK national training numbers in paediatric cardiology, adult cardiology and cardiothoracic surgery are appointed by competitive interview. ${ }^{15} 16$ There are three formal congenital heart disease surgical training programmes in the UK, often populated by trainees who have undertaken their initial cardiac surgical training outside the UK. ${ }^{1722}$ Although there is a degree of competition for certain regional ACHD training programmes, within the UK there is a shortage of applicant for posts for ACHD training particularly in comparison with training posts in other areas of cardiology. ${ }^{24} 25$ There is now a requirement for 3-6 months ACHD exposure within the first 3 years of paediatric cardiology training, however, the majority of these trainees are derived from paediatric core training and very few turn become ACHD specialists. ${ }^{15}$ In contrast, in core adult cardiology training, there is only a requirement to complete a nominal 2weeks of ACHD training, which is often delivered after subspecialty interests have been decided. ${ }^{15}$ This limited, and poorly timed, exposure to ACHD has been identified by trainees as insufficient to make an informed decision about choosing ACHD as a career path with fewer than $4 \%$ of adult cardiology trainees choosing ACHD as their subspecialty. ${ }^{24}$ UK Medical training curriculums are currently being revised. The Shape of Training report requires all adult medical specialties to dual train in acute medicine which will undoubtedly have a further detrimental impact on recruitment to and delivery of ACHD specialty training. ${ }^{26}$ If recruitment to, and expansion of ACHD consultant numbers is to be achieved via UK trainees then the training path for such specialists requires immediate review. ${ }^{25}$ An alternative or complementary strategy has included recruitment of ACHD specialists trained outside the UK. For those doctors the organisation of training is often different; congenital cardiology does not exist as a separate specialty in some healthcare settings. In most instances, substantive UK consultant appointments of non-European-trained specialists also requires judged equivalence of training abroad through the Certificate of Eligibility for Specialist Registration process. ${ }^{27}$ This is a complex process, is extremely time consuming, and requires considerable peer support. Extension of this process to European Union applicants will impose additional limitations to obtaining consultant staff from overseas whom the specialty is so reliant. ${ }^{23}$
Table 5 Entry requirements and training pathways within UK

\begin{tabular}{lll}
\hline & Entry requirements & Training pathway \\
\hline Paediatric cardiology & Level 1 paediatrics (3 years) & 5 -year higher specialty training including subspecialty training in final \\
& MRCPCH & 2 years \\
& Adult medicine core training (2 years) and level 1 paediatrics (1 year) & \\
& MRCP (UK) & \\
Cardiology & Adult medicine core training (2-3 years) & 5 -year higher specialty training including subspecialty training in final \\
& MRCP(UK) & 2 years \\
Cardiothoracic surgery & Core surgical training (2 years) & 6-year higher specialty training including congenital cardiac surgery \\
& MRCS & subspecialty training in final 2 years
\end{tabular}

${ }^{*}$ Run-through training in cardiothoracic surgery is available as 7-year programme.

$\mathrm{MRCPCH}$, Membership of the Royal College of Paediatrics and Child Health examination; MRCP(UK), Membership of the Royal College of

Physicians UK examination; MRCS, Membership of the Royal College of Surgeons examination. 


\section{Limitations}

This is a retrospective questionnaire-based study heavily reliant on the recollections of those answering the questionnaire to produce the data. The leavers themselves were not asked to give their own opinion and the reasons described may be biased by the opinions of those completing the questionnaire. Three level 1 ACHD centres did not complete the questionnaire therefore data is missing for these units although the staffing levels for 2020 could be calculated retrospectively as outlined above. Congenital cardiac care in the UK is delivered by networks which include many more consultant staff than those questioned as part of this survey. Movement of ACHD and paediatric cardiologists working in nonsurgical centres, paediatricians with an expertise in cardiology and cardiologists with an ACHD interest at non-specialist centres were not included. For the calculation of staff turnover we relied on the mean number of staff over the 10 year time period which assumes a linear change in the number of staff over this time.

\section{CONCLUSION}

Patients, families and professionals all want consistent, high-quality care that is equitably available to all congenital heart disease patients in the UK. Yet, in the last 10 years the number leaving UK practice to work abroad is equivalent to one-fifth of the current workforce with the highest turnover rate in congenital cardiac surgery. Frequent reasons given by their consultant colleagues included financial pressures, pressures relating to working in the NHS or the specialty in the UK. Significant concerns are raised in subspecialties within congenital heart disease practice and the gap between need and consultant provision is particularly startling in ACHD. This has major implications for future planning, mentoring of new consultants and staff retention within such a highly specialised service.

\section{Author affiliations}

${ }^{1}$ Paediatric and ACHD Cardiology, Freeman Hospital Cardiothoracic Centre, Newcastle upon Tyne, UK

${ }^{2}$ Paediatric Cardiology, Bristol Royal Hospital for Children, Bristol, UK

${ }^{3}$ Paediatric Cardiology, University Hospital Southampton, Southampton, UK

${ }^{4} \mathrm{ACHD}$ Cardiology, Manchester University NHS Foundation Trust, Manchester, UK

${ }^{5}$ East Midlands Congenital Heart Centre, Glenfield Hospital, Leicester, UK

${ }^{6}$ Cardiac Surgery, Bristol Royal Hospital for Children, Bristol, UK

${ }^{7} \mathrm{ACHD}$ Cardiology, Royal Brompton Hospital, London, UK

${ }^{8}$ Congenital Cardiac Centre, University Hospital Southampton, Southampton, UK

${ }^{9}$ Paediatric Cardiology, Royal Brompton Hospital, London, UK

${ }^{10}$ Director of Paediatric Echocardiography, the Evelina Children's Hospital Guy's and St Thomas' NHS Foundation Trust, London, UK

\section{Acknowledgements We would like to acknowledge Azeem Ahmad who} coordinated the survey and consultants from participating units who completed the survey.

Contributors AM, PJ, SVB-N, AC and FAB were involved in the initial design of the study. DSC and JS analysed the data and prepared the initial manuscript draft. RF, $A P, P J, P E F D$ and FAB contributed main sections of the discussion appropriate to their specialty. All authors contributed to the final manuscript with suggestions and corrections. DSC acts as guarantor.

Funding The authors have not declared a specific grant for this research from any funding agency in the public, commercial or not-for-profit sectors.

Competing interests None declared.

Patient consent for publication Not required.

Ethics approval This was a British Paediatric Cardiac Association questionnaire based study completed by its members.

Provenance and peer review Not commissioned; externally peer reviewed.

Data availability statement All data relevant to the study are included in the article or uploaded as online supplemental information.

Open access This is an open access article distributed in accordance with the Creative Commons Attribution Non Commercial (CC BY-NC 4.0) license, which permits others to distribute, remix, adapt, build upon this work non-commercially, and license their derivative works on different terms, provided the original work is properly cited, appropriate credit is given, any changes made indicated, and the use is non-commercial. See: http://creativecommons.org/licenses/by-nc/4.0/.

ORCID iD

David Steven Crossland http://orcid.org/0000-0003-3517-0483

\section{REFERENCES}

1 NHS commissioning. Congenital heart disease services. Available: https://www.england.nhs.uk/commissioning/spec-services/npc-crg/ group-e/e05/ [Accessed 14 Mar 2021].

2 The Bristol Royal Infirmary Inquiry. Available: https://webarchive. nationalarchives.gov.uk/20090811143810/http://www.bristol-inquiry. org.uk/final_report/report/index.htm [Accessed 14 Mar 2021].

3 Bower H. London Hospital orders inquiry into paediatric heart surgery deaths. BMJ 1999;319:335.

4 Report of the paediatric and congenital cardiac services review group, 2003. Available: https://webarchive.nationalarchives.gov.uk/ 20120503132544/http://www.dh.gov.uk/en/Publicationsandstati stics/Publications/PublicationsPolicyAndGuidance/DH_4070817? ssSourceSiteld=ab [Accessed 14 Mar 2021].

5 NHS specialist services. Review of children's congenital cardiac services in England. Decision making business case, 2012.

6 Independent Reconfiguration Panel. Advice on safe and sustainable proposals for children's congenital heart services. Available: https:// assets.publishing.service.gov.uk/government/uploads/system/ uploads/attachment_data/file/358762/000_S_S_report_30.04.13.pdf [Accessed 14 Mar 2021].

7 New congenital heart disease review final report. NHS England. Available: https://www.england.nhs.uk/wp-content/uploads/2015/07/ Item-4-CHD-Report.pdf [Accessed 14 Mar 2021].

8 Congenital heart disease standards and specifications. Available: https://www.england.nhs.uk/wp-content/uploads/2018/08/ Congenital-heart-disease-standards-and-specifications.pdf [Accessed 14 Mar 2021].

9 NICOR: National Institute for Cardiovascular Outcomes Research. National congenital heart disease audit website. Available: https:// nicor4.nicor.org.uk/CHD/an_paeds.nsf/vwContent/home [Accessed 14 Mar 2021].

10 National congenital heart disease audit. Summary report (2018/19 data), 2020. Available: https://www.nicor.org.uk/wp-content/uploads/ 2020/12/National-Congenital-Heart-Disease-Audit-NCHDA-FINAL. pdf [Accessed 14 Mar 2021].

11 Consultant workforce shortages and solutions: Now and in the future. BMA. Available: https://www.bma.org.uk/media/3429/ bma-consultant-workforce-shortages-and-solutions-oct-2020.pdf [Accessed 14 Mar 2021].

12 Buchan J. A critical moment: NHS staffing trends, retention and attrition. The health Foundation. February 2019. Available: https:// www.health.org.uk/sites/default/files/upload/publications/2019/A\% 20Critical\%20Moment_1.pdf [Accessed 14 Mar 2021].

13 Lambert TW, Smith F, Goldacre MJ. Why doctors consider leaving UK medicine: qualitative analysis of comments from questionnaire surveys three years after graduation. J R Soc Med 2018;111:18-30.

14 Whitehouse KJ, Jayasekera BAP, Nelson RJ. UK neurosurgical workforce planning. what changes have occurred in the consultant body 2014-2018? Br J Neurosurg 2020;34:402-7.

15 Joint Royal Colleges of Physicians Training Board. Available: https:// www.jrcptb.org.uk/ [Accessed 14 Mar 2021]. 
16 Shah R, Jahangiri M, Jones T. Congenital cardiac surgery curriculum (Sub-specialty of cardiothoracic surgery). The intercollegiate surgical curriculum programme, 2021. Available: www.iscp.ac.uk [Accessed 14 Mar 2021].

17 UK Cardiothoracic Surgery SAC and SCTS Workforce report. A report by the specialty Advisory Committee and the Society for cardiothoracic surgery in Great britain and ireland, 2019. Available: https://scts.org/wp-content/uploads/2019/01/SCTS-workforcereport-2019.pdf [Accessed 14 Mar 2021].

18 Mandalenakis Z, Giang KW, Eriksson P, et al. Survival in Children With Congenital Heart Disease: Have We Reached a Peak at $97 \%$ ? J Am Heart Assoc 2020;9:e017704.

19 Billett J, Cowie MR, Gatzoulis MA, et al. Comorbidity, healthcare utilisation and process of care measures in patients with congenital heart disease in the UK: cross-sectional, population-based study with case-control analysis. Heart 2008;94:1194-9.

20 Wren C, O'Sullivan JJ. Survival with congenital heart disease and need for follow up in adult life. Heart 2001;85:438-43.

21 Office for National statistics. Population estimates. Available: https:// www.ons.gov.uk/peoplepopulationandcommunity/populationandmig ration/populationestimates [Accessed 14 Mar 2021].
22 Westaby S, Baig K, De Silva R, et al. Recruitment to UK cardiothoracic surgery in the era of public outcome reporting. EJCTS 2015;47:679-83.

23 BMA and Brexit. Available: https://www.bma.org.uk/what-we-do/ working-with-europe/brexit/bma-and-brexit [Accessed $14 \mathrm{Mar}$ 2021].

24 et alAllen C, Joshi A, Camm F. British Cardiovascular Society. Trainee Survey, 2020. Available: http://www.bcs.com/documents/BJCA Survey Presentation_2020 - 02-07-20 FINAL.pdf [Accessed 14 Mar 2021].

25 English Ket al. Growing need for trainees in adult congenital heart disease in the UK. Br J of Cardiol 2016;23:49-50.

26 Greenaway D. Shape of training. Securing the future of excellent patient care. Final report of the independent review. Available: https://www.gmc-uk.org/-/media/documents/Shape_of_training FINAL_Report.pdf_53977887.pdf [Accessed 14 Mar 2021].

27 Certificate of eligibility for specialist registration or certificate of eligibility for GP registration application. General Medical Council. Available: https://www.gmc-uk.org/registration-and-licensing/jointhe-register/registration-applications/specialist-application-guides/ specialist-registration-cesr-or-cegpr [Accessed 14 Mar 2021]. 